\title{
8 pombalina \\ Currículo integrado e formação holística, uma experiência em cursos EFA-NS: certificação escolar
}

Autor(es): $\quad$ Lamas, Estela; Maria, Anabela; Gomes, Margarida

Publicado por: Imprensa da Universidade de Coimbra

URL

persistente: URI:http://hdl.handle.net/10316.2/31272

DOI: $\quad$ DOI:http://dx.doi.org/10.14195/978-989-26-0228-8_13

Accessed : $\quad$ 26-Apr-2023 11:41:35

A navegação consulta e descarregamento dos títulos inseridos nas Bibliotecas Digitais UC Digitalis, UC Pombalina e UC Impactum, pressupõem a aceitação plena e sem reservas dos Termos e Condições de Uso destas Bibliotecas Digitais, disponíveis em https://digitalis.uc.pt/pt-pt/termos.

Conforme exposto nos referidos Termos e Condições de Uso, o descarregamento de títulos de acesso restrito requer uma licença válida de autorização devendo o utilizador aceder ao(s) documento(s) a partir de um endereço de IP da instituição detentora da supramencionada licença.

Ao utilizador é apenas permitido o descarregamento para uso pessoal, pelo que o emprego do(s) título(s) descarregado(s) para outro fim, designadamente comercial, carece de autorização do respetivo autor ou editor da obra.

Na medida em que todas as obras da UC Digitalis se encontram protegidas pelo Código do Direito de Autor e Direitos Conexos e demais legislação aplicável, toda a cópia, parcial ou total, deste documento, nos casos em que é legalmente admitida, deverá conter ou fazer-se acompanhar por este aviso. 


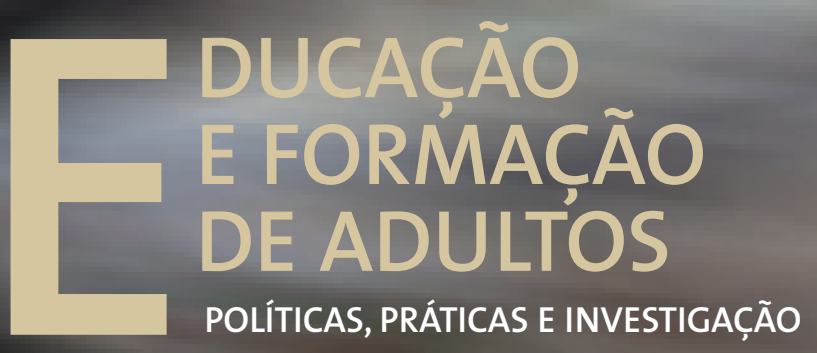

Luís Alcoforado • Joaquim Armando G. Ferreira António Gomes Ferreira • Margarida Pedroso de Lima Cristina Vieira • Albertina L. Oliveira • Sónia Mairos Ferreira 


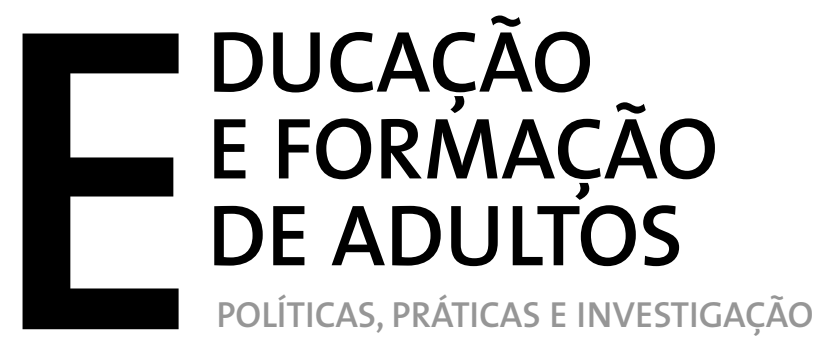

Luís Alcoforado • Joaquim Armando G. Ferreira António Gomes Ferreira - Margarida Pedroso de Lima Cristina Vieira • Albertina L. Oliveira • Sónia Mairos Ferreira 
EDIÇÃo

Imprensa da Universidade de Coimbra

URL: http://www.uc.pt/imprensa_uc

Vendas online: http://www.livrariadaimprensa.com

CONCEPÇÃO GRÁFICA

António Barros

Pré-Impressáo

SerSilito-Empresa Gráfica, Lda

EXECUÇÃo GRÁFICA

SerSilito-Empresa Gráfica, Lda

ISBN

978-989-26-0136-6

DePósito LEgaL

$340309 / 12$ 



\title{
CURrículo INTEGRAdo E FormaÇáo holística, UMA EXPERIÊNCIA EM CURSOS EFA-NS - CerTificaÇão Escolar
}

\author{
Estela Lamas \\ Anabela Maria \\ Margarida Gomes \\ Universidade de Santiago de Compostela
}

Instituiçôes internacionais têm indicado caminhos para a promoção da formação de cidadãos competentes num mundo de grandes dilemas e incertezas. Convocamos, neste sentido, o Relatório para a UNESCO de Jacques Delors (1996), que reconhece a existência de uma conjuntura específica que conduz a novos desafios colocados à Educação. Neste Relatório, Delors retoma algumas das ideias propostas por Faure nos anos 70, como por exemplo, a ideia da Educação como fundamental à vida em sociedade e à construção das ideias de paz, liberdade, justiça social e da convivência nas comunidades locais e também na 'aldeia global'. Nesta perspectiva, o que o Relatório propóe é o respeito pela diversidade, a importância da partilha entre as diferentes naçóes e povos. Lembramos ainda, nesta linha de pensamento, Robertson que, nos anos 90, apresenta a ideia do 'pensar global e agir local', baseado num conceito de práticas de negócio japonês - dochakuka - trazendo para a actualidade o conceito de 'Glocalização', de elevada importância para o mundo actual.

A Educação é pois, fulcral para a formação dos cidadãos neste começo do novo milénio, na medida em que poderá conduzir os indivíduos a melhorarem o seu auto-conhecimento e também o conhecimento do outro, conforme lembra Carneiro (2001, p. 48):

Mesmo as mais recentes medidas de competitividade evidenciam como a educação pode actuar não apenas como um contributo para a função de produção económica, mas também como uma poderosa alavanca de confiança social e de valores partilhados.

Mais recentemente, o Conselho da Europa (2009, p. 2), ao estabelecer as metas para 2020, reconhece o papel fundamental da educação perante desafios cada vez mais evidentes, tanto a nível socioeconómico e demográfico, como a nível tecnológico e ambiental. $\mathrm{O}$ mesmo documento reconhece ainda que "(...) há ainda grandes desafios por vencer para que a Europa concretize a ambição de se tornar na economia do conhecimento mais competitiva e dinâmica do mundo (...)". Face às alteraçóes operadas na sociedade e aos novos problemas que se colocam, discutimos a mudança de paradigma educacional, centrando a aprendizagem no aluno e considerando a perspectiva holística do desenvolvimento humano. Ao invocarmos para esta reflexáo o conceito grego de hólos, retomamos a ideia do homem no seu todo e, desta maneira, clarificamos a importância crucial de uma formação integral e continuada do indivíduo bem como a importância de preparar cidadáos atentos, críticos e reflexivos, tanto nas suas comunidades, como em relação ao espaço europeu e mundial.

Neste contexto de mudança, conceptualizamos a Aprendizagem ao Longo da Vida não apenas relacionada com o desenvolvimento profissional, mas particularmente como um processo continuado de aprendizagem, desde a primeira infância e que perdura ao longo das nossas vidas (Longworth, 2005; Requejo Osório, 2005), numa (re)construção permanente de nós próprios, inseridos nas nossas comunidades, com os nossos valores, considerando a nossa integração no mundo da diferença e da multiculturalidade, exercendo uma "cidadania activa". 
Também García Carrasco (2002, p. 74) refere que:

"La educación y la formación a lo largo de toda la vida es, hoy, como derecho fundamental de la persona humana, la necesidad perentoria que da contenido al derecho y deber de la educación, y no meramente el de la oportunidad formativa durante la infancia y la adolescencia. Empezamos a vislumbrar que, en nuestro contexto social, el derecho a la formación no es un derecho de la infancia, sino un derecho de la persona humana, independientemente de su situación dentro del ciclo vital".

Este pensamento é também reiterado pelas políticas europeias para a Educação, uma vez que o Conselho da Europa (op.cit. p. 3) acordou, como meta para 2020,

“(...) a aprendizagem ao longo da vida deverá ser considerada um princípio fundamental subjacente a todo o quadro, o qual deverá incluir a aprendizagem em todos os contextos, - formal, não-formal e informal - e a todos os níveis: desde a educação pré-escolar e escolar até ao ensino superior, educação e formação profissionais e educação de adultos".

Na linha de pensamento de Edgar Morin (1999), a grande razão para o fracasso da Escola encontra-se na fragmentação dos currículos. Na verdade, tenta-se espartilhar saberes quando os problemas actuais são cada vez mais complexos. Como forma de contribuir para uma praxis docente mais consentânea com este pensamento, propomos uma abordagem transversal, pluridisciplinar e transdisciplinar, nomeadamente no que concerne ao desenvolvimento dos Cursos EFA-NS de Certificação Escolar.

Para conseguir esta visão global da aprendizagem, devemos fornecer aos alunos instrumentos que lhes permitam ser aprendentes em qualquer momento e em qualquer lugar. $\mathrm{Na}$ verdade, falamos de competências que se relacionam, a nível científico, com os conhecimentos e a curiosidade e, ainda, com a autonomia, com a capacidade de comunicação, com a apropriação das novas tecnologias, ou seja, com todas as competências que possam ser relevantes para o futuro, tanto a nível prático-profissional, como cultural, cívico e emocional tal como lembra Tejadas Zabaleta (2007), ao considerar que o conceito de competência está para além do cognitivo e do laboral. Competência envolve o saber, o sentir e o fazer, ou seja, o conhecimento, as emoçóes / os afectos e a acção que, conjuntamente com o contexto, contribuem para a formaçáo e desenvolvimento do ser.

Nos dias de hoje, em que a informaçáo se propaga a uma velocidade avassaladora,

“(...) A necessidade de aquisição, por parte dos cidadãos, de competências e conhecimentos para poder tirar partido das benesses da sociedade do conhecimento, mas também fazer face aos seus desafios, é mais premente do que nunca. (...)" COM 678 (2001, p. 7).

Esta ideia de formação integral não passa apenas pela Educação formal, apesar de ser essa a nossa área central de trabalho. Consideramos que as aprendizagens não formais e informais são de importância fundamental para implementar o trabalho a que nos propomos, uma vez que o que se pretende é desenvolver uma aprendizagem centrada essencialmente no aprendente, valorizando as suas experiências anteriores.

O Programa 'Novas Oportunidades', em vigor em Portugal, desde 2006, ao centrar o processo de Aprendizagem dos Adultos numa construção curricular flexível, integrada e adaptada e no 
desenvolvimento de competências essenciais a cidadãos, activos, conscientes e reflexivos, vem ao encontro das propostas internacionais traçadas para a Educação de Adultos [EA], reforçando a consciência da necessidade de potenciar as qualidades humanas que, nos Cursos de Certificação Escolar, poderão emergir numa 'actividade integradora' na qual os alunos evidenciam as aprendizagens. Esta é a nossa perspectiva de trabalho, ao nível dos cursos EFA-NS. Parece-nos importante, pois, reflectir sobre aspectos fulcrais no desenvolvimento do Desenho curricular.

Neste sentido, é crucial pôr em prática um currículo mais flexível e implementar um desenho didáctico negociado e partilhado, que desencadeie condições para desenvolver uma perspectiva holística da formação, tal como se infere das recomendações da OCDE (2004, p. 5): “Teaching methods especially tailored to adult needs have to be developed. Another requirement is for greater flexibility in the scheduling that takes into account the practicalities of adult learners' life situations."

Destacamos, assim, o envolvimento de alunos e professores na programação, agentes que, participam directa e activamente no processo de uma aprendizagem (re)interpretada quotidianamente no trabalho colegial.

Parece-nos importante, então, reflectir sobre o desenvolvimento do Desenho curricular desta modalidade de EA, pelo menos na forma como a (re)interpretamos, em consonância com outros docentes da equipa pedagógica e, particularmente, com a docente com quem trabalhamos em codocência. Para tal, partilhamos uma experiência de implementação dos Núcleos Geradores 'Equipamentos e Sistemas Técnicos' - nas Áreas de Formação Sociedade, Tecnologia e Ciência [STC] e Cultura, Língua e Comunicação [CLC] e 'Programação', em Cidadania e Profissionalidade [CP], tendo em vista, tal como é proposto no Referencial de Competências-Chave (2006), uma 'actividade integradora' que, de acordo com o referido documento, permita a mobilização de diferentes competências, num contexto próximo e consequentemente significativo para o aluno.

Assim, este desenho curricular integrado é constituído por duas vertentes:

(i) a dos conteúdos e

(ii) a do aperfeiçoamento de competências, que a título de exemplo enumeramos:

1. Nível do saber fazer

a. planeamento e construção de projectos;

b. investigação;

c. utilização das TIC;

d. utilizaçáo de técnicas de modelos de comunicação oral e escrita de acordo com as necessidades e os contextos;

e. execução do projecto;

f. reflexão.

2. Nível do saber ser e saber estar / nível emocional

a. superar ansiedades;

b. gerir contratempos;

c. gerir entusiasmos e medos;

d. gerir satisfação e orgulho;

e. reflexão.

3. Nível do saber

a. aplicação de conhecimentos adquiridos de forma formal, informal e não formal relacionados com as temáticas abordadas. 


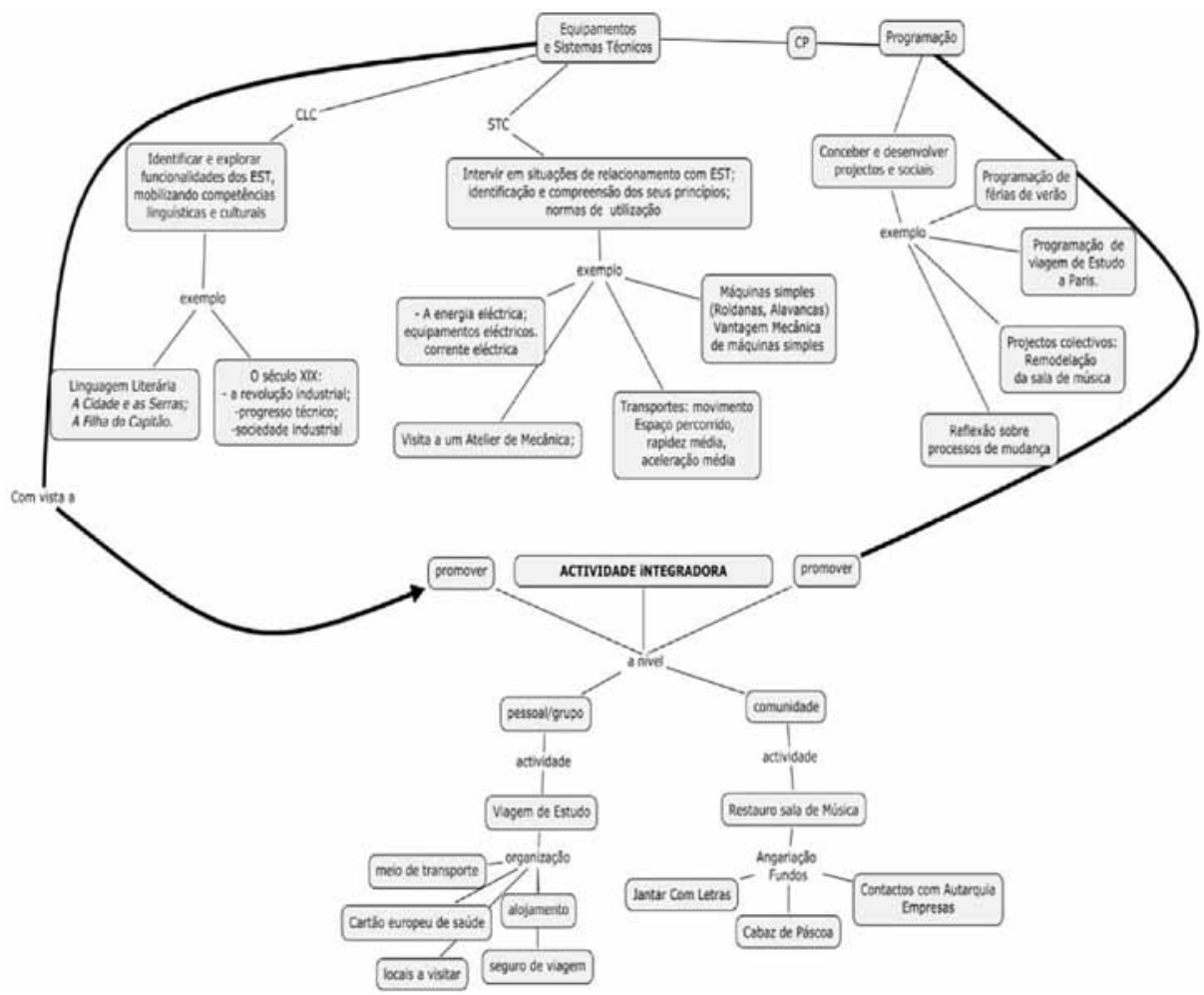

Fig. 1. Conteúdos abordados na articulação de Programação (CP) e Equipamentos e Sistemas Técnicos (STC e CLC)

Em termos metodológicos, salientamos o Instructional System Design [ISD] como o mais adequado ao tipo de trabalho desenvolvido e ao perfil dos alunos adultos com quem trabalhamos. De acordo com Broderick (2001), o ISD é a arte / ciência de criar um ambiente de aprendizagem e materiais que permitam ao aluno passar do estado do "não ser capaz", de desempenhar certas tarefas, para o estado do "ser capaz". Pretende, no fundo, a criaçáo de materiais que permitam colmatar as lacunas nas competências dos alunos, levando-os a saber fazer. Tenta, fundamentalmente, levar os aprendentes à resolução de problemas e à tomada de decisões - partindo da análise de necessidades, passando à identificação de problemas e seguindo depois a abordagem 'ADDIE': analysis, design, development, implementation e evaluation.

$\mathrm{O}$ 'desenho instrucional' considera todos os elementos necessários para uma experiência de aprendizagem de sucesso, baseada na pesquisa prática; deve considerar a compreensão das motivaçóes humanas, os seus conhecimentos prévios - aprendizagem significativa (interesses, processos e ritmos de aprendizagem), o que em nosso entender está em sintonia com a filosofia dos Cursos EFA-NS e com a nossa postura enquanto docentes. É, portanto, uma modalidade de trabalho que se centra na Aprendizagem por problemas, que envolve o estudante no seu processo de aprendizagem e que se desenvolve em quatro fases distintas, de acordo com Merril (2002), o qual apresenta uma variação ao modelo ISD: 
(i) activação da experiência;

(ii) demonstração de competências;

(iii) aplicação das competências;

(iv) integração dessas competências na vida quotidiana.

Esta variação do Modelo ISD, intitulada por Merryll, Pebble-in-the-Pond Model, livremente traduzida por nós como 'Pedrada no Charco', considera que os assuntos / conteúdos a serem abordados são referidos no início do processo, tal como fazemos nos cursos EFA. A orientação tutoria do professor vai diminuindo à medida que as tarefas se vão desenrolando, promovendo, desta forma, a autonomia dos alunos. Com este modelo, e ainda de acordo com Merryll (s/d), a Aprendizagem é facilitada pois as actividades deverão:

(i) activar conhecimentos anteriores relevantes;

(ii) proporcionar aos aprendentes o relacionar conhecimentos, o relembrar, o chamar o conhecimento de experiências anteriores relevantes, que podem ser usadas na fundação de novos conhecimentos;

(iii) demonstrar os novos conhecimentos a adquirir, mais do que informar sobre eles;

(iv) proporcionar oportunidades aos aprendentes de aplicar os novos conhecimentos a novas situaçóes (resolução de problemas);

(v) proporcionar a oportunidade de publicamente demonstrar a aquisição do conhecimento, de reflectir sobre isso e de discutir e defender esse conhecimento;

(vi) permitir aos aprendentes criar, inventar, explicar novas e pessoais formas de usar o conhecimento e as capacidades.

Como resultado deste trabalho de desenho curricular articulado, elaborado pelos docentes da equipa com um contributo forte dos alunos, desta metodologia centrada na resolução de problemas a actividade integradora desdobrou-se assim em duas grandes actividades com dois níveis de implicaçáo:

(i) pessoal e dinâmica do grupo;

(ii) intervenção comunitária.

No primeiro caso, destacamos a organização e realização de uma viagem de Estudo a Paris, que envolveu diferentes saberes - desde questóes logísticas como a marcaçáo de voos; a procura e marcação de hotel; o planeamento orçamental; a definição do melhor roteiro, tendo em conta o tempo disponível; a organização de bagagem, entre outros. No segundo caso, o Restauro de uma sala de Educação Musical da Escola. Nesta actividade, destacamos, para além de todo o conhecimento necessário à resolução de aspectos logísticos relacionado com pedido de autorização à Direcção da Escola, pedidos de patrocínios e orçamentos, recuperando os saberes adquiridos em contextos informais e não formais de aprendizagem. $\mathrm{Na}$ verdade, esta actividade foi grandemente favorecida por todo um 'know-how' que os alunos traziam de contextos exteriores à escola - profissionais e não só. Destacamos que a possibilidade que lhes foi dada de mostrarem as suas capacidades - que "não tinham sido ensinadas por nós" - envolveu-os muito na realização da actividade, bem como despertou um sentimento de orgulho face ao produzido que ultrapassou qualquer expectativa da nossa parte. 


\section{Referências Bibliográficas}

Broderick, C. L. (2001). “Instructional System Design; What it’s all about”. Versão electrónica disponível em http://www.geocities.com/ok_bcurt/ISDallabout.htm. Acedido em 23 de Dezembro de 2008.

Carneiro, R. (2001). Fundamentos da Educação e da Aprendizagem, 21 Ensaios para o Século 21. Vila Nova de Gaia: Fundação Manuel Leão.

Comissão Europeia. (2001). Tornar o Espaço Europeu de Aprendizagem ao Longo da Vida uma Realidade COM 678. Bruxelas: Comissão Europeia.

Conselho da Europa (2009). Informações oriundas das Instituições e dos Órgãos da União Europeia - Conclusóes do Conselho de 12 de Maio de 2009 sobre um quadro estratégico para a cooperação europeia no domínio da educação e da formação («EF 2020»). In Jornal Oficial da União Europeia. Bruxelhas: C 119/02.

Delors, J. (1996). Educação, Um Tesouro a Descobrir, Relatório para a UNESCO da Comissão Internacional sobre a Educação para o Séc. XXI. Porto: Edições Asa.

Finkel, D. (2008). Dar Clase con la Boca Cerrada. Valência: Publicações da Universidade de Valência.

Garcia Carrasco, J. (2002). "La Educación de Personas Adultas en el Contexto de la Sociedad de la Información”. In Aula. Salamanca: Universidade de Salamanca.

Gomes, M. do C. (2006). Referencial de Competências - Chave para a Educação e Formação de Adultos, Nivel Secundário. Lisboa: Direcção Geral de Formação Vocacional.

Jaeger, W. (s/d). Paideia, A Formação do Homem Grego. Lisboa: Editorial Aster.

Lamas, E. P. R. (Coord). (2000). Dicionário de Metalinguagens da Didáctica. Porto: Porto Editora.

Lamas, E., Maria, A., Gomes, M. (2008). "Educação e Formação de Adultos, Nível Secundário - do Desenho Curricular ao Desenho Didáctico". In Actas do X Congresso da Sociedade Portuguesa de Ciências de Educação. Bragança: IPB.

Longworth, N. (2005). El Aprendizaje a Lo Largo de La Vida en La Práctica, Transformar la educación en el siglo $X X I$. Barcelona: Paidós.

Merril, M. D. (2002). "A Pebble-in.the-Pond Model for Instructional Design”. In Performance Improvement, vol 41, n. ${ }^{\circ}$, [documento em pdf], disponível em http://cito.byuh.edu/merrill/text/papers/pebbleinthepond. pdf, acedido a 26 de Dezembro de 2008.

Merril, M. D. (s/d). First Principles of Instruction. [documento em pdf online] disponível em http://cito.byuh. edu/merrill/text/papers/Reiser\%20First\%20Principles\%20Synthesis\%201st\%20Revision.pdf, acedido a 23 de Dezembro de 2008.

Roberson, R. (s/d). The Conceptual Promise of Glocalization: Commonality and Diversity. [documento online] disponível em http://artefact.mi2.hr/_a04/lang_en/theory_robertson_en.htm, acedido a 20 de Fevereiro de 2011.

Tejadas Zabaleta, A. (2007). "Desarrollo y Formación de Competencias: un Acercamiento desde la Complejidad”. In Acción Pedagógica, n. 16. Colombia: Universidade del Valli-Calli.

Zabalza, M. A. (2008). "Curso de Doutorado Perspectivas Didácticas em Áreas Curriculares, Curso Desenho e Desenvolvimento Curricular", Guións para o Seguimento do Curso. Vila Nova de Gaia: Instituto Piaget.

Zabalza, M. A. (2007). Diseño y Desarrollo Curricular. Madrid: Narcea, S.A. Ediciones. 

Série Documentos

Imprensa da Universidade de Coimbra

Coimbra University Press

2011

- U

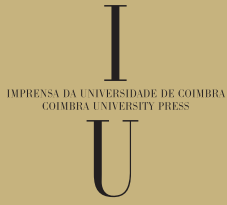

